\title{
El ahorro como estrategia de intervención social para la superación de la pobreza: estudio cualitativo sobre experiencias de ahorro de personas chilenas*
}

\author{
Saving as a Social Intervention Strategy for Overcome Poverty: \\ Qualitative Study about Saving Experiences of Chilean People
}

Recibido: 1 de marzo de 2015 | Revisado: 1 junio de 2015 | Aceptado: 1 agosto de 2015

\author{
ANDREA JARAMILLO ** \\ Universidad Alberto Hurtado, Santiago, Chile \\ MARIANNE DAHER *** \\ Universidad San Sebastián, Santiago, Chile.
}

doi:10.11144/Javeriana.up14-4.aeis

Para citar este artículo: Jaramillo, A., \& Daher, M. (2015). El ahorro como estrategia de intervención social para la superación de la pobreza: estudio cualitativo sobre experiencias de ahorro de personas chilenas. Universitas Psychologica, 14(4), 1269 . 1284. http://dx.doi.org/10.11144/Javeriana.up14-4. aeis

* El estudio que da origen a estos resultados fue solicitado y financiado por el Instituto de Estudios Peruanos a través del Proyecto Capital que cuenta con el apoyo de la Fundación Ford y el International Development Research Centre de Canadá (IDRC). Se cuenta con su autorización para publicar los resultados.

** Facultad de Psicología, Universidad Alberto Hurtado, Almirante Barroso 26, Santiago, Chile. Email: ajaramillo@uahurtado.cl

**** Escuela de Psicología, Pontificia Universidad Católica de Chile. Facultad de Psicología, Universidad San Sebastián.

\section{RES U MEN}

Vivir en situación de pobreza obliga a implementar estrategias de subsistencia, siendo un desafío generar recursos para cubrir gastos básicos, por lo que pensar en el ahorro resultaría algo ajeno. Este artículo analiza las experiencias de ahorro de un grupo de chilenos/as en situación de pobreza. Se realizó un estudio cualitativo con 70 personas en seis grupos focales. Inicialmente, señalan no ahorrar, pero emergen en sus discursos estrategias de ahorro e identifican facilitadores y obstaculizadores, produciéndose además un efecto de aprendizaje al compartir sus experiencias. Se concluye que sí es posible ahorrar y se reflexiona sobre la importancia de incluirlo en intervenciones sociales públicas y privadas que apuesten por la educación financiera como herramienta para la superación de la pobreza.

Palabras clave

ahorro; pobreza; superación de la pobreza; intervención social; estudio cualitativo

\footnotetext{
A B S T R A C T

Living in poverty forces to implement subsistence strategies, being a challenge generate resources for covering basic expenses, so wanting to save would be something prohibited. This article analysis experiences about saving of Chilean people in poverty situation. A qualitative study which 70 people in 6 focus groups was conducted. Initially, participants didn't recognize that they save, but then it emerges from their speeches saving strategies, identifying facilitators and obstacles for saving. Collectively share these experiences produces an effect of learning about saving among the participants. We concluded that it is possible to save and we reflect about the importance of including this in public and private social interventions related to financial education as a tool for overcoming poverty.

Keywords

saving; poverty; overcoming poverty; social intervention; qualitative research
} 
Las personas que viven en situación de pobreza tienen el desafío cotidiano de generar recursos económicos y manejarlos de manera adecuada para cubrir sus gastos básicos. Cualquier gasto extra puede implicar un desajuste en su precaria economía, que está construida sobre la base de necesitar cantidades de dinero mayores a las que suelen tener. Una forma confiable y sustentable para obtener dinero y enfrentar una situación de emergencia es el ahorro (Rutherford, 2002). Sin embargo, es común escuchar que las personas en situación de pobreza "viven al día", por lo que no les es posible proyectarse en el mediano o largo plazo. En este contexto, el ahorro es visto como una posibilidad que queda reservada solo para quienes tienen más ingresos, siendo una alternativa marginal para personas en situación de pobreza (Thomas \& Sinha, 2009). Esta creencia se ha discutido teóricamente, dándose razones desde la economía para desmentirlo y demostrar que personas en situación de pobreza sí podrían ahorrar (Rutherford, 2002), pero a nivel empírico es escasa la información sobre ahorro en pobreza, vacío que este artículo busca abordar desde la experiencia de personas chilenas.

Entre los pocos estudios sobre el ahorro destaca uno realizado en Perú (Trivelli \& Yancari, 2008), que caracteriza a través de una encuesta los motivos para ahorrar que tienen personas en situación de pobreza (por ejemplo, para los hijos, para enfrentar una enfermedad, para obtener una vivienda), las estrategias para lograrlo (como ahorrar parte del sueldo y disminuir algunos gastos cotidianos) y los facilitadores u obstaculizadores relativos al espacio donde se realiza el ahorro (un lugar seguro donde conservar el dinero, si es de acceso fácil o no). Otros estudios dan cuenta de los efectos del ahorro en el aumento de los ingresos de las familias, identificando mejoras sobre la alimentación, educación, salud y vivienda (Duflo, Gale, Liebman, Orszag, \& Sáez, 2006; Zapata et al., 2003). Además, existe cierta evidencia sobre el vínculo entre ahorro y empoderamiento. Si bien el uso de este concepto proveniente de la psicología comunitaria (Montero, 2003; Rappaport, 1984; Silva \& Martínez, 2004)se puede cuestionar en los estudios revisados, debido a su visión economicista (basada meramente en el manejo de los ingresos), igualmente, aportan luces interesantes para mirar esta relación. Muestran, específicamente, que el ahorro genera mayor independencia económica en las mujeres (que suelen ser las usuarias principales de los programas de microfinanzas en general) y que les otorga una sensación de control sobre la administración económica de sus hogares, pudiendo proyectar gastos futuros (Ashraf, Parlan, \& Yin, 2010; Trivelli \& Yancari, 2008; Zapata et al., 2003).

Otros resultados de los estudios muestran efectos del ahorro sobre la capacidad de toma de decisión en aspectos económicos, familiares y personales; señalando además que contar con dinero permite financiar proyectos y adquirir bienes propios, teniendo consecuencias positivas sobre la valoración personal y la autonomía (Ashraf et al., 2010; Trivelli \& Yancari, 2008; Zapata et al., 2003). Los autores concluyen que el ahorro estaría asociado a una sensación de satisfacción y orgullo, sin embargo, la información disponible no permite identificar ni profundizar en aspectos personales y sociales que promueven o dificultan el ahorro.

Incentivar el ahorro no ha sido en Chile una práctica sistemática en la política social de intervención en pobreza, por lo que resulta necesario indagar experiencias implementadas en otros países. De los informes revisados, cabe señalar que desde el punto de vista metodológico, analizan los programas desde una perspectiva cuantitativa, por lo que resulta pertinente complementar esta información con las experiencias y significados que las propias personas asignan al ahorro.

Una experiencia internacional es el caso del "Programa Capital", iniciativa impulsada por la Fundación Ford en América Latina. La versión de este programa en Perú incentivó el ahorro por medio de la asignación de subsidios y educación financiera para la apertura y uso de cuentas de ahorro en instituciones financieras formales. El principal efecto del proyecto es que las participantes efectivamente incrementaron sus ahorros a lo largo del proyecto, reduciendo así su vulnerabilidad (De los Ríos \& Trivelli, 2011; Trivelli, Montenegro, \& Gutiérrez, 2011). En Bolivia, primero se desarrolló un programa rural de microcrédito con servicios 
complementarios de promoción del ahorro, donde las participantes lograron acumular dinero que usaron para el consumo de sus hogares, suavizando los déficit estacionales y aumentando el gasto asociado al bienestar familiar (Asociación de Instituciones Financieras para el Desarrollo Rural [FINRURAL], 2003). Luego, estos resultados dieron pie a la creación de un programa orientado directamente al incentivo del ahorro (Gómez, Lemaitre, Sandoval, Monje, \& Asturizaga, 2011). En México, también se comenzó a implementar un programa de incentivo al ahorro asociado al programa de transferencias monetarias condicionadas (Campos, 2010; Chiapa, 2012). En Colombia, se tienen resultados sobre un programa de incentivo al ahorro que mostró preliminarmente efectos favorables sobre la capitalización y bienestar de los participantes (Marulanda, Paredes, \& Fajury, 2012; Salas, 2013).

La única experiencia de incentivo del ahorro, implementada y evaluada en Chile, consiste en un programa basado en el compromiso grupal, por medio de reuniones semanales de monitoreo y reconocimiento público (Kast, Meier, \& Pomeranz, 2012). Sus resultados muestran que los grupos de autoayuda de pares se constituyen en un mecanismo importante para superar los problemas de autocontrol, aumentando el ahorro de los participantes.

Tomando en cuenta los beneficios del ahorro, en tanto favorece la capitalización así como empodera a las personas, pareciera ser una estrategia que podría apoyar la superación de la pobreza y resultaría acorde tanto a los principios como a las estrategias de la intervención social comunitaria. Lo anterior en consideración de los contenidos políticos e ideológicos que están detrás de las iniciativas de microfinanzas, tanto privadas como estatales, y a una visión crítica de su posibilidad (o intención) de realmente operar como herramientas de política social de superación de la pobreza, que debieran estar éticamente orientadas hacia el bienestar y empoderamiento de las personas y comunidades. Al respecto, es importante reflexionar que si bien las microfinanzas han aparecido en el mundo de la pobreza como una estrategia de superación que ha tenido logros importantes, también presentan varias limitaciones. Muy populares han sido los programas de microcréditos, sin embargo, muchos de ellos responden a los valores y la lógica neoliberal que promueve el individualismo, la vulnerabilidad y aumenta las desigualdades (Ackerly, 1995; Goetz \& Gupta, 1996; Kabeer, 1994; Mayoux, 1998, 1999). Además, se pueden sumar voces críticas, tanto académicas como políticas, frente a la entrega de subsidios y bonos, que se ven como estrategias asistencialistas que no ayudan a resolver el problema de la pobreza y la desigualdad. Muchas de estas estrategias resultan tener fuertes rasgos paternalistas, actitud contra la cual la psicología comunitaria se ha manifestado desde sus raíces (Montero, 1984, 2004).

Considerando los antecedentes anteriores, se planteó un estudio cuyo objetivo general fue describir y analizar -a través del discurso narrativo de los participantes- los elementos claves involucrados en las posibilidades de ahorro de familias chilenas en situación de pobreza. El trabajo se realizó en el marco de un convenio entre el Fondo de Solidaridad e Inversión Social FOSIS del Ministerio de Desarrollo Social de Chile y el Instituto de Estudios Peruanos. Fue financiado por el Instituto de Estudios Peruanos a través del Proyecto Capital que cuenta con el apoyo de la Fundación Ford y el International Development Research Centre de Canadá (IDRC). El acceso a las familias se llevó a cabo a través del Programa Puente, iniciativa estatal que orienta su trabajo a familias chilenas en situación de pobreza, y es ejecutado por las municipalidades (Gobierno local), siendo sus objetivos específicos brindar apoyo psicosocial, entregar subsidios monetarios y acceso preferente a programas de asistencia y promoción social (Ministerio de Planificación [MIDEPLAN], 2004). Al momento de realizar el estudio no se ejecutaba ninguna iniciativa de ahorro vinculada a este programa ni a ninguna otra iniciativa estatal.

El estudio se desarrolló desde una mirada social comunitaria, considerando que la pobreza sigue siendo una problemática que afecta a un porcentaje significativo de la población mundial y que la psicología comunitaria tiene una misión que cumplir, buscando estrategias concretas que permitan a las personas y comunidades mejorar sus vidas, asumiendo un rol protagónico en sus procesos de cambio. 


\section{Método}

Se acometió un estudio cualitativo de carácter descriptivo y relacional, trabajando desde la perspectiva de la Grounded Theory (Glaser \& Strauss, 1967; Strauss \& Corbin, 2002). En el presente artículo, se sintetizan los principales resultados descriptivos, que caracterizan los diversos comportamientos de ahorro en las familias, ayudando a reflexionar sobre las necesidades y requerimientos de intervención en la temática de ahorro y pobreza, especialmente considerando la pertinencia de implementar estrategias desde la lógica de la intervención social comunitaria.

\section{Participantes}

Participaron 70 usuarios/as pertenecientes al Programa Puente del Sistema de Protección Social Chile Solidario, de tres regiones del país (seleccionadas fundamentalmente por su ubicación geográfica: norte, centro y sur del país). Siguiendo el muestreo de casi típico (Patton, 1990), se incluyeron participantes "promedio", sin destacar por características particularmente positivas ni negativas en relación con su participación en el programa. En cada región, se incluyeron personas de zonas urbanas y rurales.

En concordancia con la distribución de hombres y mujeres en el programa, la mayoría de los participantes del estudio fueron mujeres. Considerando el promedio de edad de los usuarios/as, se invitó a participar a personas que tuvieran entre 25 y 49 años, habiendo algunas personas de mayor edad. En la Tabla 1 se presenta el lugar de residencia, sexo y número de participantes de cada uno de los seis grupos focales realizados:

\section{Instrumento}

La información fue producida a través de grupos focales, técnica que intenta acceder a estructuras sociales o características que no son de naturaleza netamente individual o particular, sino que refieren a una matriz común de significados. De esta manera, se obtiene información relativa a experiencias personales concretas, pero también el discurso social o la representación a nivel social de la temática en estudio. La conversación en cada grupo estuvo orientada por un guion, cuyos temas centrales fueron: 1) sus experiencias e importancia atribuida al ahorro (indagando a nivel general y profundizando en la factibilidad e importancia de ahorrar en sus vidas y familias en particular), 2) los facilitadores y obstaculizadores del ahorro a nivel individual, familiar y social y 3) los apoyos que debiera entregar un programa para incentivar el ahorro.

\section{Procedimiento}

Para seleccionar a los participantes se analizaron las bases de datos del Sistema de Protección Social Chile Solidario y se escogieron aproximadamente 50 personas de cada una de las seis comunas. A través de los encargados zonales y de los agentes de intervención que trabajan directamente con las familias

\section{TABLA 1}

Localidad, sexo y número de participantes por grupo focal

\begin{tabular}{clccc}
\hline $\mathrm{N}^{\circ}$ Grupo Focal & Comuna & Hombres & Mujeres & Total \\
\hline 1 & Lo Prado y Pudahuel (Metropolitana, centro) & 2 & 7 & 9 \\
\hline 2 & Talagante (Metropolitana, centro) & 1 & 11 & 12 \\
\hline 3 & San Clemente (Maule, sur) & 0 & 13 & 13 \\
\hline 4 & Retiro (Maule, sur) & 0 & 13 & 13 \\
\hline 5 & Monte Patria (Coquimbo, norte) & 0 & 11 & 11 \\
\hline 6 & Coquimbo (Coquimbo, norte) & 0 & 12 & 12 \\
\hline & Total & 3 & 67 & 70 \\
\hline
\end{tabular}

Fuente: elaboración propia 
en el marco del Chile Solidario, se estableció contacto con las personas hasta asegurar una asistencia promedio de 10 participantes en cada grupo focal. Los grupos fueron dirigidos por una misma dupla de profesionales. Cada participante firmó un consentimiento que aseguraba la voluntariedad de participar y su anonimato en documentos e informes.

\section{Análisis de datos}

Siguiendo los procedimientos de codificación de la Grounded Theory (Glaser \& Strauss, 1967; Strauss \& Corbin, 2002), se realizaron análisis descriptivos (codificación abierta) y relacionales (codificación axial y selectiva), presentándose en este artículo los principales resultados descriptivos, producto de la codificación abierta. Para realizar los análisis, los grupos focales fueron transcritos, compartiendo las transcripciones de los primeros grupos con los integrantes del equipo ampliado (solicitantes del estudio), a fin de efectuar análisis conjuntos que permitieron triangular los realizados por las investigadoras y acometer las modificaciones pertinentes al guion, para continuar con la producción de información y con los siguientes análisis.

\section{Resultados}

A continuación, se presentan los principales resultados descriptivos, organizados según las temáticas más relevantes que emergieron del discurso de los participantes: (a) Nociones de ahorro, (b) Facilitadores del ahorro, (c) Obstaculizadores del ahorro y (d) Estrategias de ahorro. Para cada temática, se presenta un relato que incluye las categorías de análisis y una selección de citas textuales de los grupos focales, a fin de acercar al lector el discurso de las personas participantes. Se incluyen figuras que ayudan a seguir la estructura de los resultados.

\section{Nociones de ahorro}

Al iniciar las conversaciones emergen espontáneamente expresiones como es difícil, es un sacrificio, cuesta mucho, y algunos asocian el ahorro defi- nitivamente con que es imposible. No obstante lo anterior, algunas de las personas que participaron en los grupos describieron experiencias pasadas y/o actuales de ahorro. Lo más relevante es que hubo unanimidad en considerar que, a pesar de ser difícil o lejano, el ahorro es una práctica deseable, reconociendo su importancia y utilidad, permitiendo ser más feliz o tener una vida mejor.

Para los participantes que viven en comunas del sector urbano de la capital, el ahorro significa fundamentalmente juntar dinero para luego utilizarlo en diferentes cosas orientadas a mejorar la calidad de vida. En este sentido, el ahorro está asociado al trabajo y a la posibilidad de apartar parte de los ingresos para el ahorro, expresando frecuentemente trabajar para ahorrar. En las zonas rurales y en regiones, las primeras asociaciones que hacen al ahorro implican evitar ciertos gastos, por ejemplo, reducir el consumo de servicios básicos (luz, agua, gas) y de alimentos. Esta última noción está íntimamente ligada a la estacionalidad de las posibilidades laborales, siendo el ahorro una estrategia de subsistencia para los meses en que no tienen oportunidades de trabajo, consistiendo en este caso en guardar para cuando no se tenga después. Haciendo referencia a cubrir los gastos mínimos de los meses de invierno, una persona plantea:

\footnotetext{
Nosotros vivimos en (...) una comuna de pura fruta, donde trabaja toda la familia: los hijos, el marido, la mujer. Entonces, ahí nosotros empezamos a juntar plata y ahorramos para cuando llegue el invierno, que es una estación en que no pasa nada, no hay trabajo. Entonces, ahí uno, yo por lo menos, junto para el agua, la luz, cosas extras y ahorramos, comprando mercadería para guardar (...). Esto todos los años en el verano, para tener para comer en el invierno, igual que las hormiguitas. (GF 3)
}

Destaca una atribución de género respecto al ahorro, puesto que las participantes de los grupos focales señalan que las mujeres serían más organizadas, lo que contribuye al ahorro familiar. Sin embargo, también se realizan relatos sobre mujeres que serían más "consumistas" o "derrochadoras", 
y maridos que deben instarlas a comprar menos, juntar dinero y pagar al contado:

(...) y nos vimos en la obligación de abrir el tarro [donde ahorraban] iy tenía casi $\$ 50.000$ ! Y me decía: 'viste que igual sirve' y desde entonces él rompió casi todas las tarjetas de crédito y me dice 'de ahora en adelante nos vamos a tener que esforzar y comprar las cosas al contado". (GF 2)

\section{Facilitadores del ahorro}

Los aspectos que los participantes detectaron como facilitadores del ahorro refieren a: (a) elementos sociales, (b) características personales, (c) momentos del ciclo vital, (d) pasar por experiencias negativas y (e) tener un propósito claro. En la Figura 1, se sistematizan los principales resultados en relación con los facilitadores del ahorro, que luego serán explicados.

Un primer conjunto de aspectos que facilitan el ahorro, mencionados por los participantes, corresponden a Elementos Sociales, fundamentalmente contar con un trabajo estable. Los participantes de zonas rurales y urbanas relevan la importancia del trabajo para el ahorro, pues permite anticipar los ingresos y gastos, destinar un monto fijo para el ahorro y ser constante. Al mismo tiempo, destinar parte de los ingresos mensuales al ahorro es posible al recibir un sueldo digno o suficiente para cubrir gastos y apartar para el ahorro. En algunos casos se alude a la posibilidad de ahorrar los bonos recibidos por el Estado, cuando se está en algún programa estatal. Ligado a esto último, los participantes señalan como un gran facilitador del ahorro su promoción por parte de agencias públicas o privadas, mencionando el apoyo recibido por parte de algunos organismos gubernamentales y no gubernamentales. Una de las participantes señala al respecto:

De repente saber aprovechar las oportunidades que uno tiene, al menos yo he sido apoyada y me he metido siempre en lo que es el [nombra una institución], en distintas cosas donde me han apoyado para tener mi negocio de ropa americana, apoyan económicamente y apoyan también en cómo llevar el negocio, cómo hacer las cosas y he tenido suerte de tener esa ayuda. Y eso como que a uno le enseñan a ahorrar. (GF 1)

Los participantes señalan que el ahorro va acompañado de ciertas Características Personales que lo promueven. Varias personas mencionan el ser sacrificado/a como una característica que propicia el ahorro, tomando en cuenta la dificultad de ahorrar y que para lograrlo se deben postergar ciertas necesidades, lo cual se asocia a ser una persona esforzada, particularmente para quienes consideran que el ahorro es muy difícil. También se menciona la fuerza de voluntad asociada a la austeridad y la

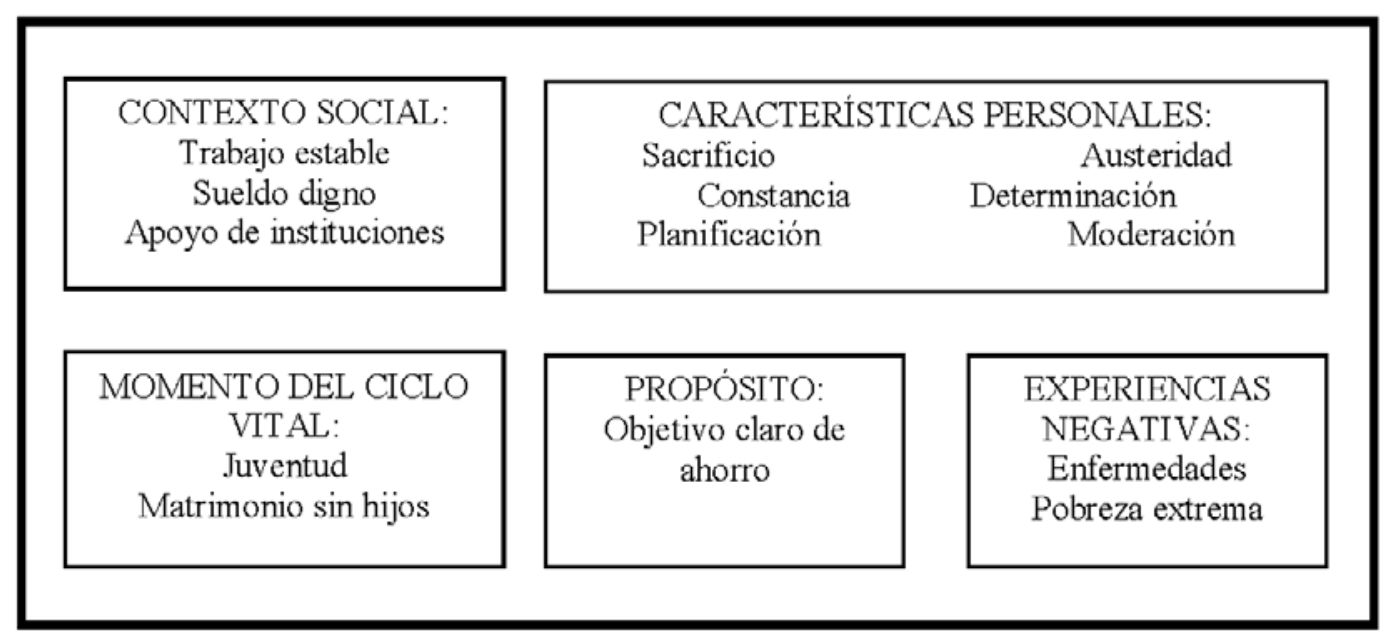

Figura 1. Facilitadores del ahorro

Fuente: elaboración propia 
constancia que permite realizar aportes regulares en el tiempo, respetando el monto destinado para el ahorro. Otro aspecto personal que promueve el ahorro es la determinación, es decir, "tener la decisión de tener algo". Se señala como promotora del ahorro la capacidad de planificar, concretamente, de lograr distribuir adecuadamente el ingreso en cosas importantes y restringir los gastos innecesarios. Por último, se menciona que ser una persona moderada permite tener cuidado al momento de adquirir deudas, aprendiendo a "no encalillarse tanto" y preferir comprar al contado.

Por otro lado, los participantes identifican facilitadores para el ahorro según el Momento del Ciclo Vital individual o familiar. Señalan que para los jóvenes sería más fácil ahorrar, puesto que tienen más oportunidades laborales o pueden desempeñarse de forma independiente, por ejemplo, trabajar en supermercados como reponedores o como vendedores. Sin embargo, coinciden en que el principal riesgo de la juventud es el uso de sustancias y secundariamente el consumismo. Los participantes también indican que a los matrimonios sin hijos puede resultarles más fácil ahorrar, pues tienen menos gastos.

Destaca entre los participantes la importancia de tener un propósito, plantearse un objetivo claro para el cual ahorrar, lo que va asociado a tener conciencia sobre el ahorro y cultivar el hábito de ahorrar. Ejemplos de objetivos claros son el ahorro para la educación de los hijos, para la salud, para imprevistos o emergencias, o para adquirir bienes materiales específicos:

Yo voy a ahorrar porque tengo una perspectiva en mente, o sea, conseguir objetivos, el ahorro enfocado en conseguir objetivos. Si tengo un objetivo claro, por ejemplo, yo voy a ahorrar porque la cama de mi hijo está malita, entonces, de aquí a seis meses más yo esa cama la tengo que cambiar, ahorro para eso. Termino con eso y me planteo otro objetivo, por último para las emergencias e imprevistos que puedan ver en la familia, que siempre hay. (GF 4)

Las Experiencias Negativas o "nefastas" que afectan el bienestar familiar general o de alguno de sus miembros, son consideradas por los participantes como promotoras del ahorro, en cuanto relevan la importancia de ahorrar para prevenir nuevamente su ocurrencia. Específicamente las enfermedades, tanto de familiares (pareja o hijos) como de quien ejerce la jefatura familiar, son experiencias que dan cuenta de la importancia de ahorrar para costear estos imprevistos, tal como aparece en la cita:

Yo creo que una de las formas más rápidas de aprender [a ahorrar] es tocando fondo, que te pille algo que no puedas solucionar, como me pasó a mí con mi hija, que estaba enferma y no podía recurrir a nadie; tuve que sacar de donde fuera y hablar con el médico, entonces, es estar en la desesperación para entender que ya no te puede pillar no tener nada. (GF 1)

Haber vivido en situación de pobreza extrema $\mathrm{o}$ indigencia es una experiencia personal que para algunos motiva el ahorro, con el fin de evitar estar nuevamente en esa situación.

\section{Obstaculizadores del ahorro}

Las personas que participaron en los grupos focales detectan una serie de amenazas para el ahorro, que en algunas ocasiones corresponden a lo opuesto de un facilitador, pero en otros casos resultan más específicas. Los obstaculizadores están relacionadas con: (a) situaciones sociales, (b) características personales y (c) el momento del ciclo vital. Adicionalmente, los participantes agregan otro conjunto de obstaculizadores debidos a (d) situaciones de emergencia, imprevistos o gran necesidad. La Figura 2 sintetiza los principales obstáculos para el ahorro:

Con respecto a los Aspectos Sociales, el primer obstaculizador detectado por los participantes de zona urbana es la crisis económica internacional, que ha afectado a Chile, y a la que atribuyen una gran influencia sobre los demás obstaculizadores. El desempleo es considerado una amenaza para el ahorro y-fundamentalmente para los participantes de sectores rurales-el mayor obstaculizador para el ahorro es la inestabilidad laboral, es decir, el trabajo por temporadas. Los participantes señalan que 
vivir en el campo es en sí un obstaculizador para el ahorro, puesto que no existen oportunidades de trabajo, salvo en ciertas temporadas, particularmente para las mujeres, quienes presentan mayor dificultad para insertarse laboralmente. Una participante comparte:

Lo que pasa aquí... es que hay pocas opciones de trabajo para la mujer. No es una zona de trabajo, o sea, son seis meses de temporada -marzo, abril, mayo, junio, julio-y ya no hay más pega para la mujer. No es una zona donde tú puedas decir 'voy a entrar a trabajar y voy a ahorrar', no se puede, o sea, no se da la opción, es una zona de bajísimo empleo. (GF 3)

Tanto en el ámbito rural como urbano, se menciona la dificultad de ahorrar debido a los salarios bajos. Los ingresos son insuficientes, por lo que el sueldo en su totalidad es destinado a financiar gastos diarios, lo que impide apartar una fracción o porcentaje de la remuneración para el ahorro. Ligado a lo anterior, el alto costo de vida, vale decir, gastos cotidianos elevados asociados a alimentación, servicios básicos, educación y arriendo, hace que sea muy difícil ahorrar. Otra amenaza contextual del ahorro es endeudarse, adquiriendo tarjetas de casas comerciales y comprando a crédito productos costosos y para los cuales no se tiene capacidad de pago. Como se observa en la siguiente conversación entre participantes:
-P: Lo primero, yo creo, que antes de ser endeudada, no meterse en las tarjetas porque esas te comen el alma y todo lo que tiene uno.

-P: En que, por ejemplo, uno tiene un crédito y uno tiene que contar con esa plata para pagar, para pagar lo que pidió, porque después tiene deudas.

-P: Hay que pensar en no endeudarse no más. Si yo no voy a poder cumplir, no me meto. Igual que pedir tarjeta, ipara qué? Cuando le cobran el doble, le cobran hasta tres, cuatro veces más las casas comerciales. (GF 6)

Finalmente, cabe destacar que algunas personas señalan que los bajos intereses han sido fuente de desmotivación para continuar con el ahorro, lo que se refleja en la siguiente experiencia:

Bueno, cuando trabajaba yo bien dejaba la plata en el banco, pero después empezaron a quitarle los aumentos [intereses]. Porque cuando uno echaba plata en el banco aumentaba, pero después no sacaba nada porque quitaron todos los aumentos... Y ahí ya decidí no echar ni abonar plata. (GF 2)

Un segundo conjunto de obstaculizadores identificados por los participantes corresponde a Características Personales que perjudican el ahorro. Existe consenso en los participantes en que ser derrochador es una amenaza para el ahorro, puesto

\begin{tabular}{|c|c|c|}
\hline $\begin{array}{l}\quad \text { ASPECTOS } \\
\text { SOCIALES: } \\
\text { - Crisis económica } \\
\text { - Desempleo } \\
\text { - Inestabilidad laboral } \\
\text { - Salarios bajos } \\
\text { - Alto costo de vida } \\
\text { - Deudas } \\
\text { - Bajos intereses } \$\end{array}$ & $\begin{array}{l}\text { CARACTERÍSTICAS } \\
\text { PERSONALES: } \\
\text { - Derrochar } \\
\text { - Compararse con otros } \\
\text { - No priorizar gastos } \\
\text { - No tener hábito de } \\
\text { ahorrar } \\
\text { - Tener "vicios" }\end{array}$ & \begin{tabular}{l} 
MOMENTO CICLO VITAL: \\
- Matrimonios con hijos y madres \\
solteras \\
- Personas mayores \\
EMERGENCIAS: \\
\multicolumn{1}{c}{ EMtraordinarios de hijos } \\
- Gastos extraos / accidentes \\
- Enfermedades \\
- Celebraciones / festividades
\end{tabular} \\
\hline
\end{tabular}

Figura 2. Obstaculizadores del ahorro.

Fuente: elaboración propia 
que no se considera el ahorro dentro del presupuesto mensual y se gasta dinero en asuntos suntuarios. Otra participante asocia el consumismo a gastos innecesarios del presupuesto diario, por ejemplo, tener malos hábitos de alimentación gastando dinero en dulces, papas fritas y bebidas. El consumismo lo asocian a otra característica personal que amenaza el ahorro: el compararse con otros que tienen más y desear tener lo mismo por medio del consumo sin medidas, como explica una participante:

No vivir tanto de lo que tiene el vecino. Vivir la realidad de uno. Porque uno no tiene tanto, no tiene cómo para comprar. ¿Por qué va a aparentar lo que uno no es? Conformarse con lo que uno tiene, en el momento. (GF 6)

En este sentido, aparece en el discurso de los participantes que ser consumista implica no ser capaz de priorizar los gastos, lo cual corresponde a otra característica personal que amenaza el ahorro. Lo anterior está vinculado al cuarto obstaculizador que detectan los participantes, que es no tener el hábito de ahorrar o bien de llevar un presupuesto que considere tanto el pago de las cuentas, como destinar dinero para el ahorro. Por último, también ampliamente mencionado por los participantes, tanto de zonas urbanas como rurales, son los vicios como un gran obstaculizador para el ahorro:

-P: Muchas veces no hay para el pan, pero para vino y para cigarros hay y para el pan no hay.

-P: Si uno pensara en ahorrar todas las cajetillas [de cigarros] quedaría con cualquier plata y después dicen 'iay! no tengo ni calzones que ponerme', pero si uno sacara la cuenta mensual de lo que gasta con el vicio... (GF 4)

En particular se menciona el uso de máquinas de apuestas, lo cual se detecta en localidades rurales y en zonas urbanas, identificándose cierta tendencia a que las mujeres son las más "enviciadas", siendo muy clara la siguiente cita:

Actualmente, usted va a las panaderías, al negocio y mucha dueña de casa está jugando a las máquinas, pensando que ilusionadamente va a ganar. Puede que una vez gane, pero después se envicia y pierde más de lo que gana. (GF 2)

$\mathrm{Al}$ igual que en el apartado anterior, los participantes identifican una serie de obstaculizadores para el ahorro asociados al Momento del Ciclo Vital individual o familiar. De esta forma, y consistente con lo que ya se mencionó, los matrimonios con hijos presentarían serias dificultades para ahorrar, apareciendo los costos de tener hijos adolescentes, pero principalmente aludiendo a aquellos que tienen niños pequeños o en edad escolar. Asimismo, los nacimientos no esperados también comprenden una amenaza para el ahorro, al interrumpir los planes o proyectos personales. Las madres solteras o solas son señaladas en general con mayor dificultad para ahorrar, puesto que suelen tener mayores gastos y menores ingresos. Independientemente de si hay padre presente o no, algunas mujeres señalan que la época de crianza es un obstaculizador del ahorro en las mujeres, ya que sienten la necesidad de dejar de trabajar para poder cuidar a los hijos: "A uno, como mamá sola, salir a trabajar afuera significa dejar a los hijos y corren muchos riesgos hoy en día" (GF 5).

Destaca también que la vejez es considerada un gran obstaculizador para el ahorro, particularmente porque no se continúa trabajando y los ingresos disminuyen.

Por último, los participantes establecen que el ahorro se ve amenazado por Emergencias, ya sea situaciones imprevistas o de gran necesidad, en las que deben hacer uso del dinero ahorrado para salvar tal situación. Si bien los niños son mencionados por los participantes como de un alto costo en general -principalmente por la alimentación, educación y salud-, señalan gastos extraordinarios de los hijos como situaciones específicas de urgencia que "se comen los ahorros":

Yo estuve trabajando y junté plata y todo, y después se me fue todo eso en lo del problema del corazón de mi hija... Después la llevé a controles y, gracias a Dios, ella ya no tiene nada, o sea, eso que yo iba a ahorrar lo gasté. (GF 2) 
Las enfermedades o accidentes en la familia en general también son mencionadas por los participantes como situaciones que exigen utilizar los ahorros e incluso otras inversiones, llegando al extremo de tener que vender la casa o vehículo. Finalmente, los participantes hacen referencia a obstaculizadores del ahorro debido la necesidad de costear celebraciones ofestividades como la Navidad:

Por ejemplo, mi marido me preguntó 'iqué quieres para la Pascua?'. Mientras tenga un regalo para mis hijas, porque son chiquititas, y tengan que comer una cena digna, no me interesa... Yo, gracias a Dios, tenía unos ahorritos por ahí y ya les tengo una ropa linda, me faltan los zapatos no más. Es que a los niños uno no les puede decir 'sabes, no tengo' porque ven a los demás con juguetes y se ponen a llorar. (GF 2)

\section{Estrategias de ahorro}

Es importante volver a destacar que a pesar de las dificultades, el ahorro se considera deseable y posible, identificándose en las experiencias relatadas estrategias específicas para ahorrar. Primero, se da cuenta de prácticas que se pueden agrupar dentro del ámbito formal del ahorro, es decir, por medio de instituciones financieras, como es el caso de personas que tienen cuenta de ahorro para la vivienda o de personas que depositan regularmente una fracción de su sueldo en una cuenta de ahorro general. No obstante lo anterior, también se señala un ahorro informal, caracterizado por ser indirecto y fuera de las instituciones financieras. Este tipo de ahorro es predominante-aunque no exclusivo-en zonas rurales y con trabajos menos estables. A continuación se presenta la Tabla 2 que muestra estas estrategias y algunas citas representativas:

Una estrategia complementaria para el ahorro que es mencionada por varios participantes de sectores rurales y con trabajos estacionales, refiere a reponer el ahorro utilizado en casos de emergencia. Los participantes explican que las situaciones imprevistas suelen ser frecuentes, por lo que es relevante, una vez utilizado dicho ahorro, reponerlo lo antes posible. Esta modalidad de ahorro otorga un criterio de realidad y factibilidad para familias en situación de pobreza respecto al ahorro: "El problema es que por emergencia usé el ahorro, pero

TABLA 2

Estrategias de ahorro informal

\begin{tabular}{|c|c|}
\hline $\begin{array}{l}\text { Tener una alcancía en } \\
\text { la casa }\end{array}$ & $\begin{array}{l}\text { "Yo estoy ahorrando todos los días cien pesos. Vamos a ver hasta dónde llego. Pero es ahorro, } \\
\text { se junta. Aunque sea una monedita de cien se junta. Y hay que tener la perseverancia, de } \\
\text { acordarse de echar los cien pesos en una alcancía" (GF 6). }\end{array}$ \\
\hline $\begin{array}{l}\text { uelto' de } \\
\text { diarias }\end{array}$ & $\begin{array}{l}\text { "Ella logró juntar más de } \$ 60.000 \text { con los vueltos. Ahí hay un buen ejemplo que debiera } \\
\text { trasladarse a todas las dueñas de casa" (GF 2). }\end{array}$ \\
\hline $\begin{array}{l}\text { Ajustar el presupuesto } \\
\text { y reducir gastos diarios }\end{array}$ & $\begin{array}{l}\text { "El ahorro también en la casa, hay muchas formas de ahorro de uno como dueña de casa, } \\
\text { de hacer buen uso del agua, de no derrochar la luz, dejar los aparatos que no se ocupan } \\
\text { desenchufados. Al menos yo me preocupo de ahorrar en eso. Ya que no puedo ahorrar en plata } \\
\text { ahora, yo me preocupo de ahorrar en eso, de organizar bien toda la parte familiar" (GF 4). }\end{array}$ \\
\hline Reutilizar materiales & $\begin{array}{l}\text { "Hay personas que dicen 'voy a contratar un maestro’ y dicen ‘sabe, necesito esto y esto } \\
\text { otro'. En cambio, tú lo puedes hacer, en materiales usar tablitas que tengas por ahí, sirven. } \\
\text { Es cuestión de armar sus cosas. No es necesario comprar un material nuevo para hacer algo. } \\
\text { Incluso hasta cosas desechables" (GF 6). }\end{array}$ \\
\hline $\begin{array}{l}\text { Aprovechar las } \\
\text { condiciones del } \\
\text { campo }\end{array}$ & $\begin{array}{l}\text { "En el campo es más fácil porque ellos, por ejemplo, pueden plantar la papá, la cebolla, todas } \\
\text { esas cosas se pueden ahorrar para la gente del campo. Tampoco estoy diciendo que para ellos es } \\
\text { fácil, pero igual es más fácil porque para la gente que vive en el pueblo es más difícil porque hay } \\
\text { que comprar las papas, las cebollas, las lentejas, todo. (...). Lo que ayuda en el campo es criar } \\
\text { animales, criar aves, ahí uno tiene los huevos, tiene las gallinas en el invierno, las cazuelas; eso } \\
\text { ayuda, la gente del pueblo no tiene eso" (GF 3). }\end{array}$ \\
\hline $\begin{array}{l}\text { Juntar ingresos de } \\
\text { trabajos eventuales o } \\
\text { 'pololitos' }\end{array}$ & $\begin{array}{l}\text { "En el invierno uno anda casa por casa. Donde yo vivo, una población, el domingo vendemos } \\
\text { una empanada o completo, esas son entraditas que van quedando, no crea que uno no hace } \\
\text { esfuerzos para ahorrar" (GF 3). }\end{array}$ \\
\hline
\end{tabular}

Fuente: elaboración propia 
poco igual. Lo repongo, en el verano que hay más trabajo, lo repongo" (GF 4).

Finalmente, algunos participantes mencionan que para evitar utilizar los ahorros, la estrategia que ellos emplean consiste en dificultar el acceso al dinero ahorrado. Esta estrategia genera la ilusión de que el dinero no existe: "como que esa plata no está, como que no la tenemos, es la única forma para poder guardar". Por ejemplo, un participante esconde la libreta de ahorro y otro le entrega el dinero a una persona de confianza.

Vinculado a las estrategias destaca que los participantes refieren una formación en ahorro adquirida en distintas instancias en que se refuerza la importancia de ahorrar y se les enseña cómo hacerlo. El principal lugar de aprendizaje corresponde al propio hogar, a través del ejemplo e incentivo de los padres. Además, se menciona el aprendizaje que han alcanzado durante sus vidas de manera autodidacta e indican que se aprende a ahorrar gracias a la recomendación de personas conocidas de su comunidad. Una de las participantes muestra la influencia positiva de sus vecinas:

Es que me decían las vecinas que ahorrara y que [nombra institución financiera] era buena para dar algún avance. (...) Yo voy todos los meses, el mínimo son seiscientos pesos, pero uno no va a poner los seiscientos pesos, uno siempre pone un poquito más. (GF 4)

\section{Discusión y reflexiones}

Una de las principales conclusiones a la que se puede llegar al analizar los grupos focales es que el ahorro es un anhelo para las personas que participaron y, si bien existen barreras para conseguirlo, gran parte de ellas tiene experiencias previas de ahorro, aun cuando impliquen pequeños montos y diversos usos de esos dineros ahorrados. Por lo tanto, personas en situación de pobreza sí pueden ahorrar, al menos dentro del perfil de participantes de este estudio.

Lo segundo importante es que junto a lo que podría denominarse "ahorro directo", referido a juntar dinero, es ampliamente mencionado el "ahorro indirecto", que apunta a disminuir los gastos y de esta manera necesitar menos dinero para cubrir las cuentas de servicios básicos y alimentación. Esto es coherente con lo revisado en la literatura (Rutherford, 2002; Trivelli \& Yancari, 2008). En este sentido, todos los participantes quieren empezar a ahorrar dinero o aumentar las cantidades que hasta el momento han logrado reunir; algunas personas esperan "al menos" lograr bajar sus gastos cotidianos. Si bien se identificaron ambos tipos de ahorro en los diferentes grupos, el ahorro indirecto en algunos casos ha sido el único que han logrado realizar personas de zonas rurales y regiones, siendo más mencionado el ahorro directo en Santiago urbano.

Cabe destacar que, si bien el ahorro es algo deseable, lograrlo dependería de una serie de elementos que entran en interacción, tales como aspectos del contexto social y laboral en que se encuentran insertos, sus características personales y la vivencia de situaciones de emergencia. En este estudio, se profundizó en dichas condiciones facilitadoras u obstaculizadoras del ahorro. A nivel contextual, la condición más importante es tener un trabajo estable con una remuneración suficiente. Se observa que en Santiago urbano esto aparece vinculado a la cesantía debido a la crisis económica, en cambio en zonas rurales y regiones la falta de trabajo está asociada a la estacionalidad de los empleos donde, como en el caso de Bolivia, los ahorros permitirían suavizar este déficit (FINRURAL, 2003).

A nivel individual se mencionan características que influyen en el ahorro, como ser una persona constante y determinada, ambas relacionadas con lo encontrado en un estudio previo sobre el autocontrol (Kast et al., 2012) y con la noción de recursos involucrados en la dimensión psicológica de la pobreza (Undurraga \& Avendaño, 1997). Una persona derrochadora y que no tiene el hábito de ahorrar, probablemente se endeuda, lo que muchas veces se liga además a ciertos "vicios" como el cigarro, el alcohol y las máquinas de juego. La solución planeada por los participantes es lograr ser más austero/a, aprender a priorizar, para así planificar y organizarse, a fin de actuar con moderación y avanzar hacia la posibilidad de ahorrar. Estas características coinciden con las mencionadas en un 
estudio chileno realizado a personas de clase media, que destaca la importancia de la austeridad, el sacrificio y la organización vinculados a aprender a valorar el dinero y saber administrarlo (Coria, Tapia, Fuentealba, \& Costa, 2005).

Un aspecto interesante y que es coherente con otros estudios (Coria et al., 2005), refiere al aprendizaje sobre el ahorro, señalándose que el lugar principal es el hogar durante la época de crianza. Sin embargo, los resultados presentados en este artículo lo amplían a aprendizajes de tipo autodidacta, lo que se encuentra relacionado con una visión positiva de sí mismo y autoconfianza, que naturalmente es posible vincular con el empoderamiento a nivel individual. Aparece también el incentivo al ahorro por recomendaciones de otras personas significativas de la comunidad, particularmente vecinos, $y$ como podría llegar a ser un agente de intervención de un programa que estimulara a ahorrar.

Emerge el tema de los imprevistos o situaciones de emergencia como un gran obstaculizador, lo cual está en sintonía con lo revisado teóricamente (Rutherford, 2002). En general, se considera que pasar por experiencias duras, vinculadas fundamentalmente a necesidades de los hijos, conduce a que las personas se pongan objetivos concretos y "trabajen" para cubrir esos gastos. También se mencionan "situaciones imprevistas", a partir de las cuales se impone la voluntad de intentar prevenir nuevamente la ocurrencia de experiencias que se viven como nefastas.

Respecto a los beneficios del ahorro, resulta particularmente llamativa su asociación con el empoderamiento antes mencionada, lo que hace pensar sobre el ahorro y las características personales positivas descritas por los participantes. Si bien es necesario contar con dichas características para ahorrar, desde los reportes de los programas revisados se observa que cultivar el hábito del ahorro podría influir en desarrollar tales cualidades (Ashraf et al., 2010; Kabeer, 2001). Dado lo anterior, se podría discutir que, frente al riesgo del paternalismo en la mera asignación externa de ingresos (por medio de subsidios o bonos), aparece la alternativa del ahorro como una estrategia que aumenta efectivamente la sensación de control y el poder sobre la propia vida (Montero, 2003; Rappaport, 1984).
En el relato de las personas que participaron en los grupos focales, aparecen ciertos recursos que en caso de existir y manejarse de manera adecuada, permitirían sobrellevar los obstáculos y activar los facilitadores para ahorrar. Aun tomando en consideración que el estudio realizado no tiene pretensiones de generalización y que abre temas relevantes que resulta necesario seguir investigando (como profundizar en las diferencias urbano/rurales y regionales, además de la influencia de la dimensión de género en las conductas de consumo y ahorro), es posible concluir en torno a la importancia de incluir el ahorro en las iniciativas públicas y privadas que apuestan por la educación financiera como una herramienta de superación de la pobreza. Los resultados permiten reflexionar entonces sobre las características que debiera tener una política de ahorro, destacando tres ejes que serían centrales: (a) apoyo económico e incentivos, (b) formación y capacitación y (c) apoyo de pares y de agentes de intervención.

Respecto a lo primero, resulta evidente la relación que establecen las personas que participaron en el estudio entre la posibilidad de ahorrar y tener ingresos estables. A partir de esto, un programa de incentivo al ahorro debiera estar asociado a una actividad generadora de ingresos, ya sea un emprendimiento o inserción laboral. No obstante, destacan las experiencias efectivas de ahorro logradas por algunos participantes, lo que se contradice con este aparente requisito y abre la posibilidad del ahorro, aun no teniendo estabilidad laboral. Se pueden rescatar entonces las estrategias de ahorro directo e indirecto, como es el caso de uno de los programas revisados que promueve el ahorro de pequeñas cantidades de dinero en el hogar (por ejemplo el vuelto de las compras o el excedente de reducir servicios básicos), poniendo un impedimento físico para restringir su acceso (al tener una alcancía con seguridad) para luego depositarlo en una institución financiera formal (Ashraf et al., 2010). Además, también aparece como relevante tener incentivos para el ahorro, que toman la forma de intereses o premios por cumplimiento de metas o por la regularidad de los montos.

En relación al segundo eje, destaca que los participantes de los grupos focales no tuvieron 
mayores dificultades para "imaginar" un programa de ahorro, mostrando en general un buen manejo del tema y asignando importancia al ahorro en sus vidas. Dominan conceptos generales como ingresos, costos, ganancias, intereses y les hace sentido participar en un programa de ahorro, pero consideran fundamental que se hagan capacitaciones para tener mayor formación, formalizando algunos conocimientos ya existentes e incorporando nuevas alternativas para visualizar y planificar su ahorro. Esta estrategia de intervención va en la línea de la realizada en Perú, donde se observó que el acceso real al sistema financiero pasa por informar y educar (Trivelli \& Yancari, 2008). Desde la literatura teórica, es fundamental agregar que no solo se tiene que educar a las personas, sino también se a las instituciones financieras para que rompan el mito sobre la imposibilidad del ahorro en pobreza, y realmente crean que estas personas pueden ser potenciales clientes, ofreciendo productos adecuados a sus particularidades y servicios cercanos (locales, frecuentes, costeable, rápidos, transparentes y de fácil comprensión) (Rutherford, 2002). Por lo tanto, se requiere de instituciones comprometidas en apoyar a personas en situación de pobreza.

El tercer eje responde a la importancia otorgada a las figuras de apoyo "de carne y hueso". Por un lado, resulta relevante un agente de intervención que ayude a hacer planes individualizados y que supervise las dificultades y logros de cada participante, pero que también guíe un trabajo grupal que puede constituir un interesante recurso de apoyo. Surge desde aquí la relevancia de incluir el apoyo de pares, que es señalado directamente por las personas del estudio al comentar su participación en los grupos focales, que constituyó en sí una instancia de aprendizaje al compartir colectivamente sus experiencias e incorporar nuevas estrategias que señalaron querían comenzar a implementar en su vida diaria. Esto está en sintonía con la experiencia peruana donde el trabajo grupal y las capacitaciones generaron motivación para el ahorro, pero también propiciaron nuevos liderazgos, contribuyendo en una mejor capacidad de negociación y promoviendo la participación a distintos niveles (política, social, recreativa) (Zapata et al., 2003).
Finalmente, se considera importante reflexionar que frente a las críticas hacia las estrategias tradicionales de microfinanzas focalizadas en programas de microcréditos que se asocian a la lógica neoliberal (Ackerly, 1995; Goetz \& Gupta, 1996; Kabeer, 1994; Mayoux, 1998, 2000), se alza la idea de fomentar el ahorro como una alternativa más confiable, sustentable, potenciadora de la autogestión y de la autodeterminación. El ahorro asociado a la educación financiera surge como una estrategia de intervención innovadora para hacer manejo de los recursos personales, familiares, grupales y comunitarios, entregándole mayor protagonismo a las propias personas y no solo a instituciones externas que buscan cobrar los créditos. En este sentido, el ahorro permite que las personas y comunidades desarrollen capacidades para administrar y generar recursos. Además, el ahorro involucra un conjunto de habilidades de planificación y proyección que van más allá de lo económico, activando características potenciadoras del sí mismo y de conexión con los recursos del entorno. El ahorro, desde una ética orientada hacia al bienestar y el empoderamiento, resulta coherente con la lógica de intervención de la psicología comunitaria, que podría rebatir la expectativa social de lograr un mayor "ajuste" del individuo a la lógica del consumo, pues al entregar conocimientos y herramientas las personas y comunidades podrían manejarse mejor dentro de este sistema neoliberal, desde una perspectiva crítica y de defensa de sus derechos.

\section{Referencias}

Ackerly, B. (1995). Testing tools of development: Credit programmes, loan involvement and women's empowerment. IDS Bulletin, 26(3), 56-68. doi: 10.1111/ j.1759-5436.1995.mp26003007.x

Ashraf, N., Parlan, D., \& Yin, W. (2010). Female empowerment: Impact of a commitment savings product in the Philippines. World Development, 38(3), 333 344. doi:10.1016/j.worlddev.2009.05.010

Asociación de Instituciones Financieras para el Desarrollo Rural. (2003). Evaluación de impactos de programas para la mujer Pro Mujer - Bolivia. La Paz: Trama S.R.L. 
Campos, P. (2010). Oportunidades y desafíos para instrumentar en México Programas de Transferencias Monetarias Condicionadas sobre la base del uso de servicios de ahorro (Proyecto Capital, En Breve, N. - 20). Extraído de http://proyectocapital. org/index.php/es/documentos/item/112-en-breve20-oportunidades-y-desafios-para-instrumentaren-mexico-programas-de-transferencias-monetarias-condicionadas-sobre-la-base-del-uso-deservicios-de-ahorro

Coria, M., Tapia, M., Fuentealba, R., \& Costa, C. (2005). Socialização econômica em famílias chilenas de classe media: Educando cidadãos ou consumidores? Psicologia EO Sociedade, 17(2), 88-98.

Chiapa, C. (2012). Ahorro, contabilidad mental, ahorro por default y transferencias monetarias condicionadas: una evaluación al programa Oportunidades de México (Proyecto Capital, En Breve, N. 34). Extraído de http://proyectocapital.org/index.php/ es/documentos/item/362-en-breve-34-"ahorro-contabilidad-mental-ahorro-por-default-y-transferencias-monetarias-condicionadas"-una-evaluaciónal-programa-oportunidades-de-méxico

De los Ríos, J., \& Trivelli, C. (2011). Movilización de ahorros en programas de transferencias monetarias condicionadas: buscando impactos a mediano plazo (Proyecto Capital, En Breve, N. 23). Extraído de http://proyectocapital.org/index.php/es/documentos/item/109-en-breve-23-movilización-de-ahorrosen-programas-de-transferencias-monetarias-condicionadas-buscando-impactos-a-mediano-plazo

Duflo, E., Gale, W., Liebman, J., Orszag, P., \& Sáez, E. (2006). Saving incentives for low-and middleincome families: Evidence from a field experiment with H\&R Block. The Quarterly Journal of Economics, 121, 1311-1346. doi: 10.1093/qje/121.4.1311

Glaser, B., \& Strauss, A. (1967). The discovery of grounded theory: Strategies for qualitative research. Nueva York: Aldine Publishing.

Goetz, A. M., \& Gupta, R. S. (1996). Who takes the credit? Gender, power and control over loan use in rural credit programs in Bangladesh. World Development, 24(1), 45-63.

Gómez, F., Lemaitre, M., Sandoval, J., Monje, J., \& Asturizaga, M. (2011). Proyecto de inclusión financiera: movilización de ahorro de beneficiarios de programas de transferencias monetarias condicionadas (TMC). Informe de diagnóstico - Bolivia. (Proyecto Capital, En Breve, N.o 24). Extraído de http://proyectocapital.org/index.php/es/documentos/item/108-enbreve-24-proyecto-de-inclusión-financiera-movilización-de-ahorro-de-beneficiarios-de-programasde-transferencias-monetarias-condicionadas-tmcinforme-de-diagnóstico-bolivia

Kabeer, N. (1994). Reversed realities: Gender hierarchies in development thought. New Delhi: Kali for Women.

Kabeer, N. (2001). Conflicts over credit: Re-evaluating the empowerment potential of loans to women in rural Bangladesh. World Development, 29(1), 63-84.

Kast, F., Meier, S., \& Pomeranz, D. (2012). Under-savers snonymous: Evidence on self-help groups and peer pressure as a savings commitment device (Working Paper, № 12-060). Boston, MA: Harvard Business School.

Marulanda, B., Paredes, M., \& Fajury, L. (2012). Estudio de caso de la experiencia de un programa piloto de ahorro en Colombia (Proyecto Capital, En Breve, N.. 29). Extraído de http://proyectocapital.org/index.php/es/documentos/item/322-en-breve-29-estudio-de-caso-de-la-experiencia-de-un-programapiloto-de-ahorro-en-colombia

Mayoux, L. (1998). Participatory learning for women's empowerment in micro-finance programmes: Negotiating complexity, conflict and change. IDS Bulletin, 29(4), 39-50. doi: 10.1111/j.17595436.1998.mp29004005.x

Mayoux, L. (1999). From access to empowerment: Gender issues in micro-finance (CSD NGO Women's Caucus Position Paper for CSD-8). New York: CSD Women's Caucus. Disponible en http://citeseerx. ist.psu.edu/viewdoc/download;jsessionid $=5 \mathrm{EBC6}$ 08896B7E3F8EDCB6451FA8C50FF?doi=10.1.1.5 06.8647\& $\&$ rep $=$ rep1\& type $=$ pdf

Ministerio de Planificación (2004). Conceptos fundamentales: Sistema de Protección Social Chile Solidario. Santiago: Gobierno de Chile.

Montero, M. (1984). La psicología comunitaria: orígenes, principios y fundamentos teóricos. Revista Latinoamericana de Psicología, 16(3), 387-400.

Montero, M. (2003). El fortalecimiento en la comunidad. En M. Montero, Teoría y práctica de la psicología comunitaria. Tensión entre comunidad y sociedad (pp. 59-92). Buenos Aires: Paidós. 
Montero, M. (2004). Introducción a la psicología comunitaria. Desarrollo, conceptos y procesos. Buenos Aires: Paidós.

Patton, M. (1990). Qualitative evaluation and research methods. Newbury Park, CA: Sage.

Rappaport, J. (1984). Studies in empowerment: Introduction to the Issue. En J. Rappaport, R. Hess \& C. Swift (Eds.), Studies in empowerment (pp. 1-7). New York: The Haworth Press.

Rutherford, S. (2002). Los pobres y su dinero. México: La Colmena Milenaria \& Universidad Iberoamericana, A.C.

Salas, M. L. (2013). Compromisos públicos versus privados: el efecto de etiquetas y clasificación de cuentas mentales en el comportamiento de ahorradores de bajos ingresos en Colombia (Proyecto Capital, En Breve, N. 35). Disponible en http://proyectocapital.org/ es/publicaciones/en-breve.html?start $=20$

Silva, C., \& Martínez, M. (2004). Empoderamiento: proceso, nivel y contexto. Psykhe, 13(2), 29-39. doi: 10.4067/S0718-22282004000200003

Strauss, A., \& Corbin, J. (2002). Bases de la investigación cualitativa. Técnicas y procedimientos para desarrollar la teoría fundamentada. Medellín: Editorial Universidad de Antioquia.
Thomas, R., \& Sinha, J. (2009). Critical look at microfinance and NGO's in regard to poverty reduction for women. Social Development Issues, 31(2), 30-42.

Trivelli, C., Montenegro, X., \& Gutiérrez, M. C. (2011). Un año ahorrando: primeros resultados del programa piloto "Promoción del Ahorro en Familias Juntos" (Documento de trabajo N. ${ }^{\circ}$ 159; Serie Economía N. ${ }^{\circ}$ 51). Lima: Instituto de Estudios Peruanos. Disponible en http://archivo.iep.pe/textos/DDT/ unanoahorrando.pdf

Trivelli, C., \& Yancari, J. (2008). Las primeras ahorristas del Proyecto Corredor. Evidencia de la primera cohorte de ahorristas de un proyecto piloto (Documento de trabajo N. ${ }^{\circ} 153$; Serie Economía N. ${ }^{\circ}$ 48). Lima: Instituto de Estudios Peruanos. Disponible en http://anic.utexas.edu/project/laoap/ iep/ddt153.pdf

Undurraga, C., \& Avendaño, C. (1997). Dimensión psicológica de la pobreza. Psykhe, 6(1), 57-63.

Zapata, E., Vázquez, V., Alberti, P., Pérez, E., López, J., Flores, A., ... Garza, E. (2003). Microfinanciamiento y empoderamiento de mujeres rurales. Las cajas de ahorro y crédito en México. México: Plaza y Valdés Editores. 
